\title{
Desenvolvimento de misturas instantâneas de mandioca e caseína: efeito do teor de proteína e parâmetros de extrusão sobre a viscosidade
}

\author{
Development of instant blends of cassava flour and casein: \\ effect of protein contents and extrusion parameters on viscosity
}

\section{Beatriz Helena Borges LUSTOSA ${ }^{1}$, Magali LEONEL ${ }^{1 *}$}

\section{Resumo}

O interesse da indústria de alimentos por produtos desenvolvidos a partir de farinhas acrescidas de proteína não se deve somente às suas características nutricionais, senão também às suas propriedades funcionais e reológicas, as quais definem as suas aplicações comerciais. Este trabalho teve por objetivo avaliar o efeito de parâmetros operacionais do processo de extrusão sobre as propriedades de pasta de misturas de farinha de mandioca e caseína. O processo de extrusão seguiu o delineamento 'central composto rotacional' para três fatores: teor de proteína (2,5 a 9,5\%), umidade (14,5 a 19,5\%) e temperatura de extrusão $\left(65\right.$ a $\left.135^{\circ} \mathrm{C}\right)$. As misturas antes e após a extrusão foram analisadas no Rapid Visco Analyser (RVA) quanto a: viscosidade inicial, pico de viscosidade, quebra de viscosidade, viscosidade final e tendência à retrogradação. Os resultados obtidos nas misturas antes da extrusão mostraram aumento dos valores de viscosidade com o aumento da concentração de proteína até o ponto central (6\%) e, nos teores mais elevados de proteína, ocorreu redução destes. Após a extrusão, observou-se que o teor de proteína foi a variável de maior efeito sobre as propriedades de pasta, seguida pela umidade das misturas.

Palavras-chave: mandioca; caseína; viscosidade; extrusão.

\begin{abstract}
The interest of the food industry in products developed from flours added with protein is not due only to their nutritional characteristics, but also due to their functional and rheological properties, which define their commercial applications. This study aimed to evaluate the effect of operational parameters of the extrusion process on the paste properties of cassava flour and casein blends. The process of extrusion followed the central composed rotational design with three factors: protein content ( 2.5 to $9.5 \%$ ), moisture (14.5 to $19.5 \%$ ), and extrusion temperature $\left(65\right.$ to $\left.135^{\circ} \mathrm{C}\right)$. Before and after extrusion, the blends were analyzed on a Rapid Visco Analyser using the following parameters: initial viscosity, peak of viscosity, breakdown, final viscosity, and retrogradation tendency. Before extrusion, the product showed an increase in viscosity characteristics with an increase in the concentration of protein until to the central point (6\%). In higher levels of protein there was a reduction in the pasting properties values. After extrusion, it was observed that the amount of protein was the variable that produced the greatest effect on the paste properties followed by the moisture of the blends.
\end{abstract}

Keywords: cassava; casein; viscosity; extrusion.

\section{Introdução}

Um dos grandes problemas enfrentados pelas populações de baixa renda em todo o mundo e, principalmente nos países em desenvolvimento, é a inadequação de alimentação, a qual ocasiona quase sempre a desnutrição. O perfil alimentar do brasileiro é simples, em termos de qualidade e quantidade dietética. Dentre os alimentos de origem vegetal mais consumidos pela população, destacam-se o feijão, o arroz e a farinha de mandioca, que representam os principais produtos da cesta básica (ANGELIS, 1995; LEMOS et al., 1996; SGARBIERI, 1996).

A farinha de mandioca constitui um dos principais produtos desta raiz e seu uso é muito difundido em todo o País. A tecnologia de fabricação da farinha é simples, por isso existem no Brasil indústrias das mais variadas escalas de produção e graus de tecnificação. A produção de farinha de mandioca em 2005 foi de 2,4 milhões de toneladas, com as regiões Norte e Nordeste responsáveis por 64\% da produção (COMPANHIA..., 2006).

A farinha de mandioca tem sido pouco explorada como ingrediente em produtos de preparo instantâneo que utilizam farinhas pré-gelatinizadas de cereais e de outras tuberosas, como sopas, macarrões instantâneos, etc. (SEBIO, 1996).

A farinha de mandioca é uma rica fonte de carboidrato, contendo proteína de baixo valor biológico, por ser limitante em aminoácidos essenciais. $\mathrm{O}$ enriquecimento de produtos convencionais, largamente disponíveis e de boa aceitação pela população, com ingredientes de elevado valor nutritivo, é o caminho mais curto, e, mais econômico para se oferecer à população alimentos nutritivos a um custo competitivo com seus similares no mercado. 
As proteínas do leite compreendem duas frações: as caseínas, que se apresentam principalmente no estado de partículas coloidais, (micelas) e as proteínas do soro, que estão em solução (DAVIAN et al., 2000; GAUCHERON; LE GRAËT; BRIARD, 2000). O leite bovino tem um conteúdo de proteína, expresso como $\% \mathrm{~N} \times 6,38$, de $30-35$ g.L $\mathrm{L}^{-1}$. Ao redor de $78 \%$ destas proteínas são caseínas, organizadas na forma de micelas constituídas por $92 \%$ de proteínas e $8 \%$ de sais inorgânicos, principalmente fosfato de cálcio (SGARBIERI, 1996).

Devido ao seu elevado valor nutritivo e excelente funcionalidade, aliados ao baixo custo de produção, a caseína se apresenta como ingrediente de primeira linha para o enriquecimento e produção de alimentos para fins específicos. Ela tem sido usada na produção de produtos cárneos, produtos de laticínios, produtos de panificação, chocolates, confeitos, produtos de cobertura, cremes para café e snacks (GIESE, 1994).

A extrusão é um processo que combina várias operações unitárias, incluindo mistura, cozimento, amassamento, cisalhamento, formação e moldagem. Os dois principais fatores que influenciam nas características dos produtos extrusados são: as características das matérias-primas e as condições operacionais do extrusor. Como principais características para a matéria-prima são destacadas as seguintes: tipo de material, teor de umidade, estado físico, composição química (teores e tipos de amidos, proteínas, gorduras e açúcares) e $\mathrm{pH}$ do material. Já, como parâmetros operacionais, são apontados como importantes: temperatura, pressão, diâmetro da matriz e taxa de cisalhamento, sendo esta última influenciada pelo desenho interno do extrusor e pelo seu comprimento; além da velocidade e geometria da(s) rosca(s) (FELLOWS, 2006).

Mediante a importância da cultura da mandioca, estudos que visem o desenvolvimento de novos produtos apresentam grande interesse de produtores e industriais. Nesta linha, este trabalho teve por objetivo avaliar o efeito do teor de proteína e umidade nas misturas de farinha de mandioca e caseína, bem como, da temperatura de extrusão, sobre as propriedades de pasta das farinhas instantâneas de mandioca.

\section{Material e métodos}

As misturas de farinha de mandioca e caseína foram extrusadas em extrusor mono-rosca modelo IMBRA-RX, sob as condições fixas do processo: Taxa de compressão da rosca (4,5 $\mathrm{mm}$ profundidade e $14 \mathrm{~mm}$ de largura); Taxa de alimentação: $150 \mathrm{~g} / \mathrm{min}$; Abertura da matriz: $3 \mathrm{~mm}$; Temperatura na $1^{\text {a }}$ zona e $2^{2}$ zona: 25 e $60^{\circ} \mathrm{C}$, respectivamente; Rotação da rosca: $272 \mathrm{rpm}$ e, nas condições variáveis descritas na Tabela 1.

Tabela 1. Parâmetros variáveis do processo de extrusão.

\begin{tabular}{cclcl}
\hline \multicolumn{2}{c}{ Níveis } & \multicolumn{3}{c}{ Fatores ou variáveis independentes } \\
\hline Axiais & Codificados & $\mathrm{P}$ & $\mathrm{T}$ & $\mathrm{U}$ \\
\hline$-\alpha$ & $-1,682$ & 2,5 & 65 & 14,5 \\
& -1 & 4 & 80 & 16 \\
& 0 & 6 & 100 & 18 \\
& +1 & 8 & 120 & 20 \\
$+\alpha$ & $+1,682$ & 9,5 & 135 & 21,5 \\
\hline
\end{tabular}

P: proteína (\%); T: Temperatura de extrusão $\left({ }^{\circ} \mathrm{C}\right)$; U: Umidade das amostras (\%).
O processo seguiu o delineamento 'central composto rotacional' para três fatores, com um total de 15 tratamentos (COCHRAN; COX, 1957), a saber:

- Oito tratamentos correspondentes ao fatorial $2^{3}$, em que os três fatores são:

- $\mathrm{P}=$ teor de proteína na mistura $(\%), \mathrm{T}=$ temperatura $\left({ }^{\circ} \mathrm{C}\right)$, $\mathrm{U}=$ umidade (\%),

- Cada qual em dois níveis, codificados como -1 e +1 ;

- Seis tratamentos com níveis mínimo e máximo de cada fator, codificados como $-\alpha$ e $+\alpha$, respectivamente, sendo $\alpha=2^{3 / 4}=1,682 ; \mathrm{e}$

- Um tratamento central repetido 6 vezes, em que os fatores estão todos em um nível médio, codificado como zero.

Para a análise das propriedades de pasta das misturas antes e após a extrusão, foi utilizado o Rapid Visco Analyser (RVA). As suspensões (3,5 g de farinha em $25 \mathrm{~mL}$ de água) foram corrigidas para a base de $14 \%$ de umidade e passaram pelo programa de tempo e temperatura Extrusion 1 do software Thermocline for Windows, versão 2.2. Do gráfico obtido, foram avaliadas as seguintes características: temperatura de pasta, viscosidade máxima (pico), queda de viscosidade ou breakdown (diferença entre a viscosidade máxima e a viscosidade da pasta mantida a $95^{\circ} \mathrm{C}$ por 5 minutos), viscosidade final e tendência à retrogradação (diferença entre a viscosidade final e a viscosidade da pasta a $50^{\circ} \mathrm{C}$ por 5 minutos). A viscosidade foi expressa em RVU (NEWPORT SCIENTIFIC, 1998).

O experimento de extrusão foi conduzido num delineamento fatorial $3^{3}$ incompleto, com três fatores ou variáveis independentes, e três níveis codificados.

Para a análise estatística dos resultados experimentais foi utilizado o modelo: (Equação1)

$$
y_{k}=\mathrm{b}_{0}+\sum_{i=1}^{3} \mathrm{~b}_{i} \mathrm{X}_{i k}+\sum_{i=1}^{3} \sum_{j=1}^{3} \mathrm{~b}_{i j} \mathrm{X}_{i k} \mathrm{X}_{j k}+\mathrm{e}_{k}
$$

em que: $\mathrm{y}_{\mathrm{k}}=$ valor observado da variável dependente no nível $K$, $\mathrm{K}=1, \ldots, 20 ; \mathrm{x}_{\mathrm{iK}}=\mathrm{i}$-ésima variável independente, no nível $K, \mathrm{i}=1,2,3 ; \mathrm{b}_{0}=$ parâmetro do modelo, independente de $\mathrm{x}$; $b_{i}=$ parâmetros correspondentes aos efeitos lineares de $x_{i}$; $b_{\mathrm{ij}}=$ parâmetros correspondentes aos efeitos de $2^{\mathrm{a}}$ ordem de $\mathrm{x}_{\mathrm{i}} \mathrm{x}_{\mathrm{i}}, \mathrm{i}=1,2,3, \mathrm{j}=1, \ldots, 3 ;$ e $\mathrm{e}_{\mathrm{k}}=$ erro experimental associado à $\mathrm{k}$-ésima parcela.

O processamento dos dados e a análise estatística foram realizados com o auxílio do sistema SAS. A significância do modelo foi testada pela análise de variância (ANOVA), sendo adotado o nível de significância alfa de $5 \%$.

$\mathrm{Na}$ análise dos dados realizada pelo programa SAS, foi utilizada a análise de regressão com a opção stepwise. Inicialmente foi realizada a análise de variância sendo determinados os coeficientes de regressão do modelo incluindo todos os parâmetros. O ajuste do modelo foi feito pela opção stepwise, sendo que o modelo obtido foi validado pelo teste f utilizando-se como denominador o quadrado médio do erro puro.

$\mathrm{Na}$ construção das superfícies de resposta, duas variáveis independentes variaram dentro das regiões estudas e a terceira foi mantida fixa no ponto central. 


\section{Resultados e discussão}

A viscosidade é uma das propriedades mais importantes de misturas instantâneas. A curva de viscosidade representa o comportamento durante o aquecimento e permite avaliar as características da pasta formada, devido às modificações estruturais das moléculas de amido, e de outros componentes e, também, a tendência à retrogradação durante o resfriamento.

Os resultados obtidos para as propriedades de pasta das misturas de farinha de mandioca e caseína, nas diferentes concentrações de proteína, estão apresentados na Tabela 2.

Os resultados obtidos mostraram baixa viscosidade inicial para todas as misturas. A viscosidade inicial ou viscosidade de pasta a frio indica a capacidade das farinhas em absorver água em temperatura ambiente e formar pasta, gel ou líquido viscoso (CARVALHO; ASCHERI; CAL-VIDAL, 2002).

Com o aumento da porcentagem de proteínas na mistura, ocorreu um aumento do pico de viscosidade, da viscosidade final e da tendência à retrogradação, contudo, nas maiores

Tabela 2. Propriedades de pasta das misturas de farinha de mandioca e caseína para os diferentes teores de proteína.

\begin{tabular}{cccccc}
\hline Proteína (\%) & VI & PV & QV & VF & TR \\
\hline 2,5 & $3,5^{\mathrm{bc}}$ & $93,88^{\mathrm{c}}$ & $4,79^{\mathrm{c}}$ & $270,79^{\mathrm{c}}$ & $181,55^{\mathrm{c}}$ \\
4,0 & $2,84^{\mathrm{bc}}$ & $168,66^{\mathrm{ab}}$ & $45,71^{\mathrm{ab}}$ & $404,92^{\mathrm{b}}$ & $283,96^{\mathrm{b}}$ \\
6,0 & $5,95^{\mathrm{ab}}$ & $194,5^{\mathrm{a}}$ & $56,0^{\mathrm{a}}$ & $433,63^{\mathrm{a}}$ & $342,04^{\mathrm{a}}$ \\
8,0 & $7,67^{\mathrm{a}}$ & $155,3^{\mathrm{b}}$ & $41,92^{\mathrm{b}}$ & $399,71^{\mathrm{b}}$ & $286,34^{\mathrm{b}}$ \\
9,5 & $1,17^{\mathrm{c}}$ & $22,17^{\mathrm{d}}$ & $0,21^{\mathrm{c}}$ & $72,87^{\mathrm{d}}$ & $50,92^{\mathrm{d}}$ \\
\hline
\end{tabular}

${ }^{*}$ Médias seguidas de letras iguais na coluna não diferem entre si ao nível de $5 \%$ de significância; VI = Viscosidade Inicial; PV = Pico de Viscosidade; QV = Quebra de

Viscosidade; $\mathrm{VF}=$ Viscosidade Final; $\mathrm{TR}=$ Tendência à Retrogradação. porcentagens de proteína, foi observada diminuição desses valores, indicando interferência do teor de proteína nos parâmetros analisados.

O pico de viscosidade se refere à máxima viscosidade após o início do aquecimento e antes do início do resfriamento da suspensão no viscoamilógrafo. Durante o ciclo de aquecimento até $95{ }^{\circ} \mathrm{C}$, ocorre o intumescimento e a gelatinização dos grânulos de amido, atingindo o pico máximo nesta etapa. O maior teor de proteína pode ter interferido no processo de gelatinização do amido, o que levou a um menor pico de viscosidade nestas condições.

Maia et al. (1999), analisando a viscosidade de pasta em viscógrafo Brabender de mingaus desidratados de arroz e soja, observaram que, com o aumento das proporções de soja (0 a $50 \%$ ), houve um aumento na temperatura de viscosidade máxima e uma diminuição na viscosidade máxima, resultado também observado por Borges et al. (1998) em misturas de canjiquinha e soja.

Segundo Silveira et al. (1981), avaliando a viscosidade de misturas de farinhas de arroz e soja, observaram que o aumento da soja nas misturas diminui o teor de amido e, com isso, a viscosidade. Outro fator importante é a diminuição da água disponível para a gelatinização do amido por sua interação com a proteína.

A Tabela 3 apresenta os resultados experimentais obtidos para as propriedades de pasta das misturas extrusadas, nas diferentes condições experimentais. A partir dos resultados foram obtidos os modelos matemáticos que predizem o comportamento das variáveis estudas em relação às características físicas dos produtos extrusados (Tabela 4).

Tabela 3. Propriedades de pastas das misturas de farinha de mandioca e caseína extrusadas sob diferentes condições.

\begin{tabular}{|c|c|c|c|c|c|c|c|c|c|c|c|}
\hline \multirow[t]{2}{*}{ Trat } & \multicolumn{3}{|c|}{ Níveis codificados } & \multicolumn{3}{|c|}{ Variáveis independentes } & \multicolumn{5}{|c|}{ Variáveis dependentes } \\
\hline & $\mathrm{X} 1$ & $\mathrm{X} 2$ & $\mathrm{X} 3$ & $\mathrm{P}$ & $\mathrm{T}$ & $\mathrm{U}$ & VI & $\mathrm{PV}$ & QV & VF & TR \\
\hline T1 & 1 & 1 & 1 & 8 & 120 & 20 & 20,92 & 17,5 & 11,75 & 14,92 & 9,16 \\
\hline $\mathrm{T} 2$ & 1 & 1 & -1 & 8 & 120 & 16 & 26,83 & 28,75 & 23,08 & 22,5 & 16,83 \\
\hline $\mathrm{T} 3$ & 1 & -1 & 1 & 8 & 80 & 20 & 23,67 & 36,67 & 15,25 & 26,25 & 17,83 \\
\hline $\mathrm{T} 4$ & 1 & -1 & -1 & 8 & 80 & 16 & 21,33 & 31,58 & 17,16 & 36,58 & 22,16 \\
\hline T5 & -1 & 1 & 1 & 4 & 120 & 20 & 24,16 & 26,92 & 10,92 & 39,79 & 23,79 \\
\hline T6 & -1 & 1 & -1 & 4 & 120 & 16 & 40,42 & 41,25 & 33,67 & 22,5 & 14,92 \\
\hline T7 & -1 & -1 & 1 & 4 & 80 & 20 & 20,66 & 18,62 & 9,33 & 22,12 & 12,83 \\
\hline $\mathrm{T} 8$ & -1 & -1 & -1 & 4 & 80 & 16 & 26,58 & 27,33 & 23,58 & 9,58 & 5,83 \\
\hline T9 & 0 & 0 & 0 & 6 & 100 & 18 & 18,71 & 21,92 & 13,62 & 24,16 & 15,87 \\
\hline T9 & 0 & 0 & 0 & 6 & 100 & 18 & 21,75 & 25,04 & 15,46 & 29,04 & 19,46 \\
\hline T9 & 0 & 0 & 0 & 6 & 100 & 18 & 20,25 & 19,29 & 10,87 & 26,92 & 18,51 \\
\hline T9 & 0 & 0 & 0 & 6 & 100 & 18 & 20,33 & 22,67 & 14,67 & 25,17 & 17,17 \\
\hline T9 & 0 & 0 & 0 & 6 & 100 & 18 & 23,04 & 20,25 & 13,04 & 24,96 & 17,75 \\
\hline T9 & 0 & 0 & 0 & 6 & 100 & 18 & 23,17 & 25,75 & 17,67 & 23,67 & 15,59 \\
\hline $\mathrm{T} 10$ & $-1,69$ & 0 & 0 & 2,5 & 100 & 18 & 12,87 & 36,37 & 9,79 & 78,54 & 51,96 \\
\hline $\mathrm{T} 11$ & 1,69 & 0 & 0 & 9,5 & 100 & 18 & 5,08 & 4,83 & 3,51 & 2,08 & 0,76 \\
\hline $\mathrm{T} 12$ & 0 & $-1,69$ & 0 & 6 & 65 & 18 & 24,83 & 27,08 & 16,75 & 26,58 & 16,25 \\
\hline $\mathrm{T} 13$ & 0 & 1,69 & 0 & 6 & 135 & 18 & 35,33 & 31,17 & 19,84 & 26,25 & 14,92 \\
\hline $\mathrm{T} 14$ & 0 & 0 & $-1,69$ & 6 & 100 & 14,5 & 45,75 & 49,25 & 41,33 & 23,17 & 15,25 \\
\hline $\mathrm{T} 15$ & 0 & 0 & 1,69 & 6 & 100 & 21,5 & 36,83 & 39,75 & 30,33 & 23,67 & 14,25 \\
\hline
\end{tabular}

$\mathrm{X} 1=\mathrm{P}=$ teor de Proteína na mistura (\%); $\mathrm{X} 2=\mathrm{T}=$ Temperatura de extrusão $\left({ }^{\circ} \mathrm{C}\right) ; \mathrm{X} 3=\mathrm{U}=$ Umidade da mistura (\%); VI = Viscosidade Inicial (RVU); $\mathrm{PV}=\mathrm{Pico}$ de Viscosidade $(\mathrm{RVU})$; $\mathrm{QV}=$ Quebra de Viscosidade (RVU); VF = Viscosidade Final (RVU); TR = Tendência à Retrogradação (RVU). 
Tabela 4. Modelos matemáticos para as propriedades de pasta das misturas extrusadas.

\begin{tabular}{llrrr}
\hline \multicolumn{1}{c}{ Modelo codificado } & Nível de significância & $\mathrm{R}^{2}$ & \multicolumn{1}{c}{$\mathrm{F}_{\text {calculado }}$} & \multicolumn{1}{c}{$\mathrm{F}_{\text {tabelado }}$} \\
\hline $\mathrm{VI}$ & $\mathrm{y}=21,26-2,36 \mathrm{x}_{1}+2,76 \mathrm{x}_{2}-2,98 \mathrm{x}_{3}-4,65 \mathrm{x}_{4}+2,81 \mathrm{x}_{5}+6,77 \mathrm{x}_{6}-1,82 \mathrm{x}_{7}+2,33 \mathrm{x}_{8}-2,32 \mathrm{x}_{9}$ & $95 \%(\mathrm{p}<0,05)$ & 0,984 & 68,08 \\
$\mathrm{PV}$ & $\mathrm{y}=22,79-3,86 \mathrm{x}_{1}+7,05 \mathrm{x}_{6}-5,53 \mathrm{x}_{7}$ & $95 \%(\mathrm{p}<0,05)$ & 0,623 & 8,88 \\
$\mathrm{QV}$ & $\mathrm{y}=15,05-5,03 \mathrm{x}_{3}-3,30 \mathrm{x}_{4}+7,01 \mathrm{x}_{6}+2,97 \mathrm{x}_{8}$ & $95 \%(\mathrm{p}<0,05)$ & 0,871 & 25,20 \\
$\mathrm{VF}$ & $\mathrm{y}=26,42-8,96 \mathrm{x}_{1}$ & $95 \%(\mathrm{p}<0,05)$ & 0,267 & 6,57 \\
$\mathrm{TR}$ & $\mathrm{y}=17,05-5,68 \mathrm{x}_{1}$ & $95 \%(\mathrm{p}<0,05)$ & 0,245 & 5,06 \\
\hline
\end{tabular}

$\mathrm{X}_{1}=$ teor de proteína (linear); $\mathrm{X}_{2}=$ Temperatura (linear); $\mathrm{X}_{3}=$ Umidade (linear); $\mathrm{X}_{4}=$ proteína (quadrático); $\mathrm{X}_{5}=$ temperatura (quadrático); $\mathrm{X}_{6}=$ umidade $(q u a d r a ́ t i c o) ; \mathrm{X}_{7}=$ proteína $\times$ temperatura; $\mathrm{X}_{8}=$ proteína $\times$ umidade; $\mathrm{X}_{9}=$ temperatura $\times$ umidade.

A viscosidade inicial ou viscosidade de pasta a frio indica a capacidade das farinhas em absorver água em temperatura ambiente e formar pasta, gel ou líquido viscoso (CARVALHO; ASCHERI; CAL-VIDAL, 2002). Os resultados obtidos nas farinhas extrusadas de mandioca e caseína para este parâmetro variaram de 5,08 a 45,75 RVU. Considerando que as misturas de farinha de mandioca e caseína, nas diferentes concentrações de proteína, antes do processo de extrusão apresentavam viscosidade inicial próxima de zero, o processo de extrusão aumentou significativamente este parâmetro.

A análise dos coeficientes de regressão mostrou ter ocorrido influência significativa de todos os fatores sobre a viscosidade inicial dos produtos extrusados. As superfícies de resposta referentes à Viscosidade Inicial (VI) dos produtos extrusados mostram que nas condições de elevada temperatura e baixos teores de proteína a VI foi maior (Figura 1). Mantendo-se a temperatura de extrusão constante em $100^{\circ} \mathrm{C}$, observa-se que, nas condições de umidade intermediária e elevado teor de proteína na mistura, a viscosidade inicial é menor (Figura 2). Com o teor de proteína fixo em 6\% (ponto zero), as maiores viscosidades iniciais são obtidas nas condições de elevada temperatura e baixa umidade, conforme demonstrada na superfície de resposta da Figura 3.

No caso de tratamentos de extrusão não tão severos, determinada porcentagem de grânulos de amido pode conservar parte da estrutura amilácea, apresentando um pico no perfil amilográfico, que significa amido não gelatinizado ou parcialmente gelatinizado (GUHA; ALI; BHATTACHARYA,1998).

Os valores de viscosidade inicial se elevam com a prévia gelatinização da amostra e decrescem em condições severas de processamento em razão da despolimerização do amido com a cocção (MENEGASSI et al., 2007).

Os resultados obtidos para o Pico de Viscosidade (PV) dos produtos extrusados nas diferentes condições de processo variaram de 4,83 a 49,25 RVU. A análise dos coeficientes de regressão mostrou ter havido influência significativa do teor de proteína e umidade nas misturas e da interação entre os fatores temperatura e umidade sobre este parâmetro.

Na condição de elevada umidade e baixo teor de proteína, o pico de viscosidade é maior, sendo que, nas condições de baixo teor de proteína e elevada temperatura de extrusão, com a umidade constante em $16 \%$, ocorrem os maiores valores de pico de viscosidade (Figuras 4 e 5).

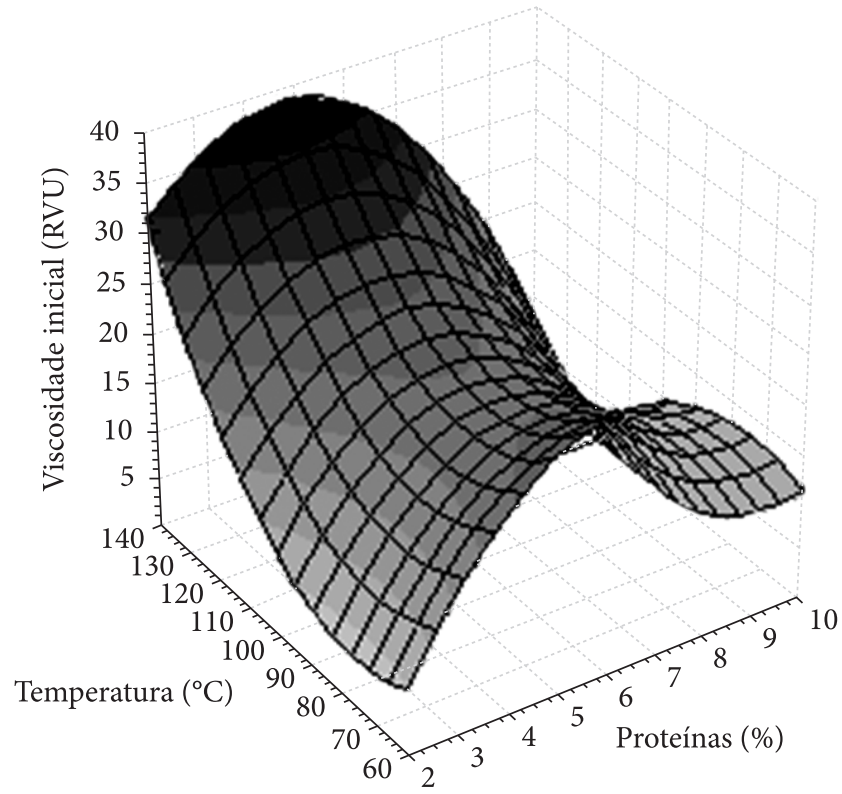

\begin{tabular}{|llll|}
$\square 3,514$ & $\square 7,028$ & $\square 10,541$ & $\square 14,055$ \\
$\square 17,569$ & $\square 21,083$ & $\square 24,597$ & $\square 28,110$ \\
$\square 31,624$ & $\square 35,138$ & $\square$ Above & \\
\hline
\end{tabular}

Figura 1. Efeito do teor de proteínas e da temperatura de extrusão sobre a Viscosidade Inicial (VI) das misturas extrusadas, com a umidade de $18 \%$.

A viscosidade a quente está diretamente relacionada com o nível de degradação sofrido pelo grânulo de amido. Quando a estrutura do grânulo é destruída, ele perde sua capacidade de inchar quando aquecido em água e, consequentemente, apresenta baixa viscosidade a quente (CLERICI; EL-DASH, 2008).

Whalen et al. (1997), avaliando as condições operacionais na extrusão de misturas de farinhas de arroz, trigo e milho, com a temperatura variando de 160 a $190^{\circ} \mathrm{C}$ e a rotação mantida em $200 \mathrm{rpm}$, observaram que a diminuição da umidade de 29 para $15 \%$ resultou em redução significativa do pico de viscosidade das amostras.

Menegassi et al. (2007), avaliando o efeito das condições de extrusão sobre a viscosidade de farinha de mandioquinhasalsa, observaram que com o aumento da umidade na farinha ocorreu uma tendência à maiores picos de viscosidade após a extrusão, o que pode ser devido ao menor atrito promovido nestas condições. 


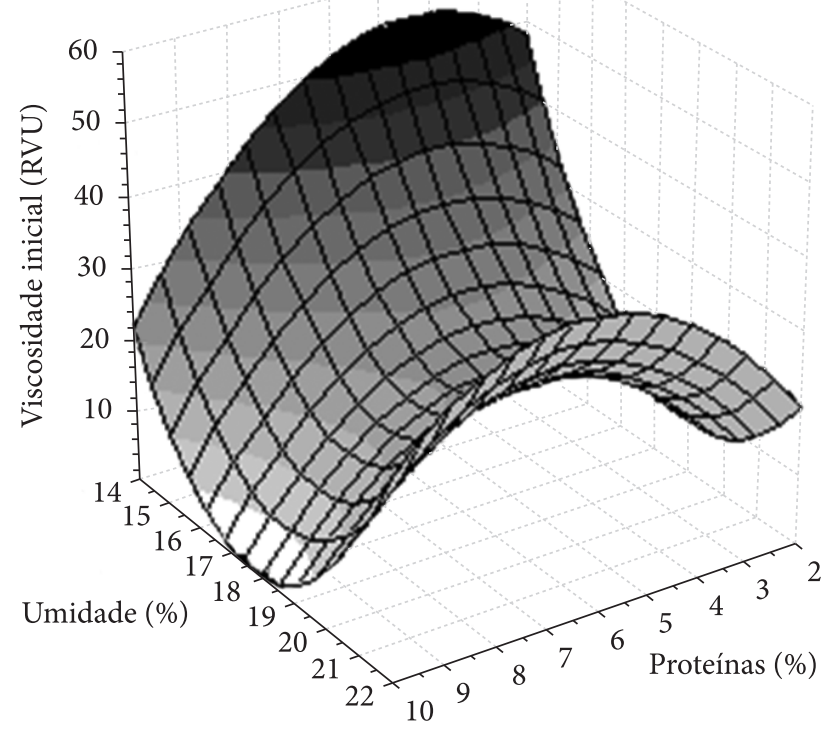

$$
\begin{array}{llll}
\square 4,949 & \square 9,899 & \square 14,848 & \square 19,797 \\
\square 24,747 & \square 29,696 & \square 34,645 & \square 39,595 \\
\square 44,544 & \square 49,493 & \text { above } &
\end{array}
$$

Figura 2. Efeito do teor de proteínas e da umidade sobre a Viscosidade Inicial (VI) das misturas extrusadas, com a temperatura de extrusão de $100{ }^{\circ} \mathrm{C}$.

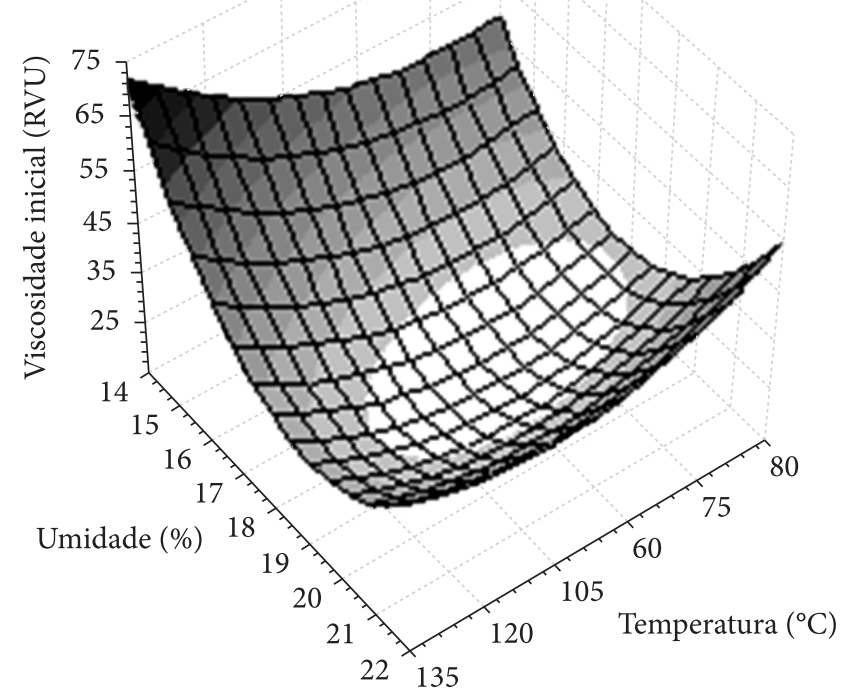

\begin{tabular}{|llll|}
\hline$\square 25,684$ & $\square 30,355$ & $\square 35,025$ & $\square 39,696$ \\
$\square 44,366$ & $\square 49,037$ & $\square 53,707$ & $\square 58,378$ \\
$\square 63,049$ & $\square 67,719$ & $\square$ Above & \\
\hline
\end{tabular}

Figura 3. Efeito da umidade e da temperatura de extrusão sobre a Viscosidade Inicial (VI) das misturas extrusadas, com $6 \%$ de proteína na mistura.

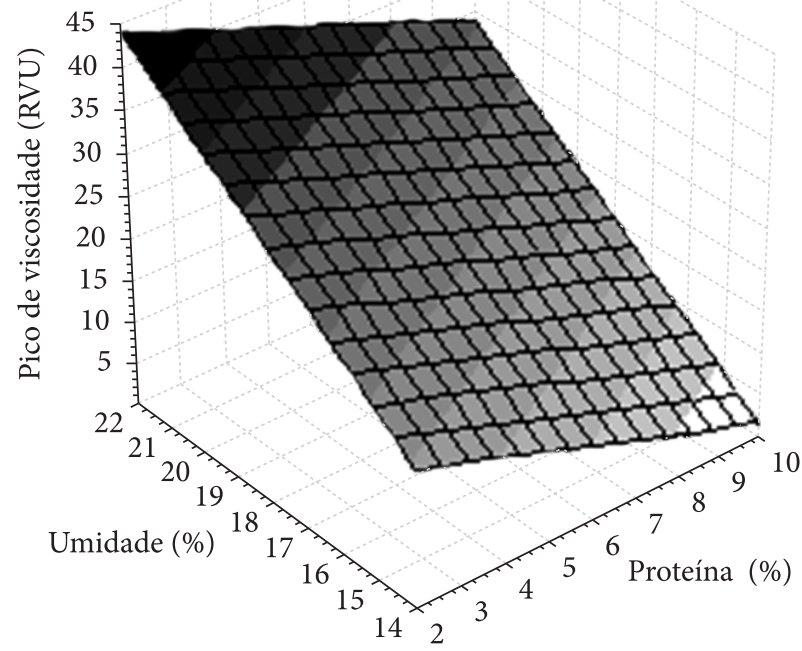

$\begin{array}{llll}\square 5,480 & \square 9,311 & \square 13,162 & \square 17,013 \\ \square 20,864 & \square 24,716 & \square 28,567 & \square 32,418 \\ \square 36,269 & \square 40,120 & \square \text { Above } & \end{array}$

Figura 4. Efeito da umidade e do teor de proteína sobre o Pico de Viscosidade $(\mathrm{PV})$ das misturas extrusadas, com a temperatura de extrusão de $100^{\circ} \mathrm{C}$.

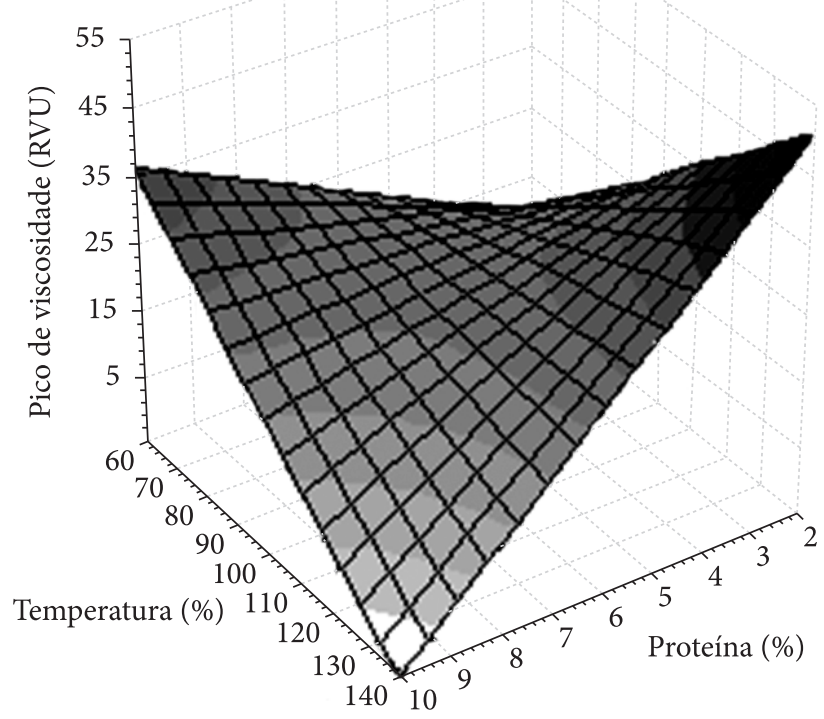

$$
\begin{array}{llll}
\square 0,102 & \square 5,205 & \square 10,307 & \square 15,410 \\
\square 20,512 & \square 25,615 & \square 30,717 & \square 35,820 \\
\square 40,922 & \square 46,024 & \text { घ Above } &
\end{array}
$$

Figura 5. Efeito da temperatura de extrusão e do teor de proteína sobre o Pico de Viscosidade (PV) das misturas extrusadas, com a umidade de $18 \%$. 
El-Saied et al.(1979) constataram que o conteúdo de proteína é negativamente correlacionado com a viscosidade máxima. A proteína pode atuar como uma barreira física para o intumescimento do amido, uma vez que os grânulos de amido são encaixados na matriz de proteína.

De acordo com os resultados, pode-se observar que a quebra de viscosidade variou de 3,51 a 41,33 RVU. A análise dos coeficientes de regressão mostrou terem ocorrido efeitos significativos do teor de proteína e da umidade. Nas condições de alta umidade e baixo teor de proteína a quebra de viscosidade é menor (Figura 6).

A viscosidade final das farinhas extrusadas de mandioca e caseína variou de 2,08 a 78,54 RVU. Considerando a variação observada nas farinhas mistas antes da extrusão $(72,87$ a 433,63 RVU), ocorreu uma redução significativa deste parâmetro após a extrusão das misturas. A análise de regressão mostrou ter ocorrido o efeito do teor de proteína sobre a VF dos produtos extrusados. Com o teor de umidade mantido em $16 \%$ e a temperatura de extrusão no ponto central $\left(100{ }^{\circ} \mathrm{C}\right)$, a viscosidade final dos produtos extrusados decresce com o aumento do teor de proteína nas misturas (Figura 7).

Os valores da tendência à retrogradação dos produtos extrusados variaram de 0,76 a 51,96 RVU, e, dentre os parâmetros avaliados, somente a proteína teve efeito significativo sobre a retrogradação. Através do modelo matemático do modelo ajustado construiu-se o gráfico referente ao efeito da concentração de proteína na mistura sobre a tendência à retrogradação dos produtos extrusados (Figura 8). Os resultados mostraram que nas condições de elevado teor de proteína, com

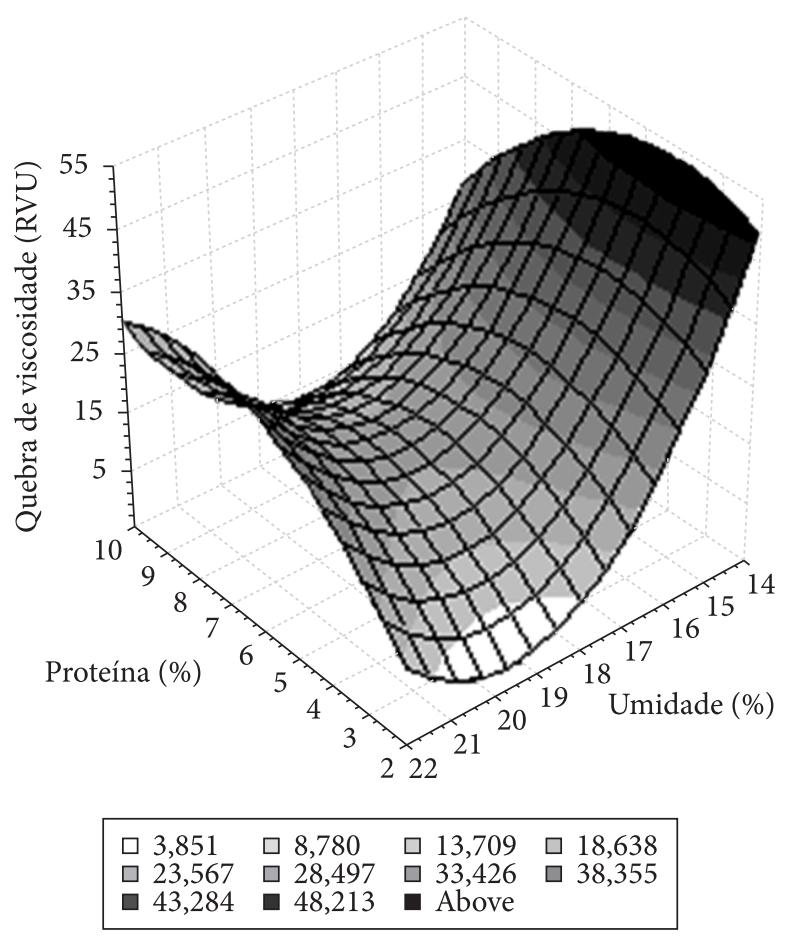

Figura 6. Efeito da umidade e do teor de proteína sobre a Quebra de Viscosidade (QV) das misturas extrusadas, com a temperatura de extrusão de $100^{\circ} \mathrm{C}$. a umidade e a temperatura no ponto central, a tendência à retrogradação é menor.

A retrogradação do amido ocorre por efeito da recristalização das moléculas de amilose e amilopectina, decorrente do agrupamento das partes lineares das moléculas de amido através da formação de novas ligações de hidrogênio, resultando na formação de precipitados e/ou géis (GUTKOSKI; EL-DASH, 1999).

Uma característica marcante de todas as farinhas extrusadas é a de não apresentar aumento de viscosidade com o abaixamento da temperatura de 95 para $50^{\circ} \mathrm{C}$, contrariamente ao que se observou nas mesmas farinhas mistas enquanto cruas. Esse fenômeno talvez possa ser explicado pela baixa retrogradação do amido após a extrusão e pela incapacidade das proteínas, já desnaturadas pela extrusão, formarem géis, mediante aquecimento e resfriamento (ALVIM; SGARBIERI; CHANG, 2002).

Wang et al. (2005), avaliando as propriedades de pasta e absorção de água das farinhas de trigo e soja (90:10), pré-cozidas por extrusão em diferentes umidades e temperaturas de barril, observaram que a viscosidade a frio, a $25^{\circ} \mathrm{C}$, das farinhas de trigo e soja (90:10) pré-cozidas, aumentou com o aumento da temperatura de extrusão, e a elevação da umidade resultou,

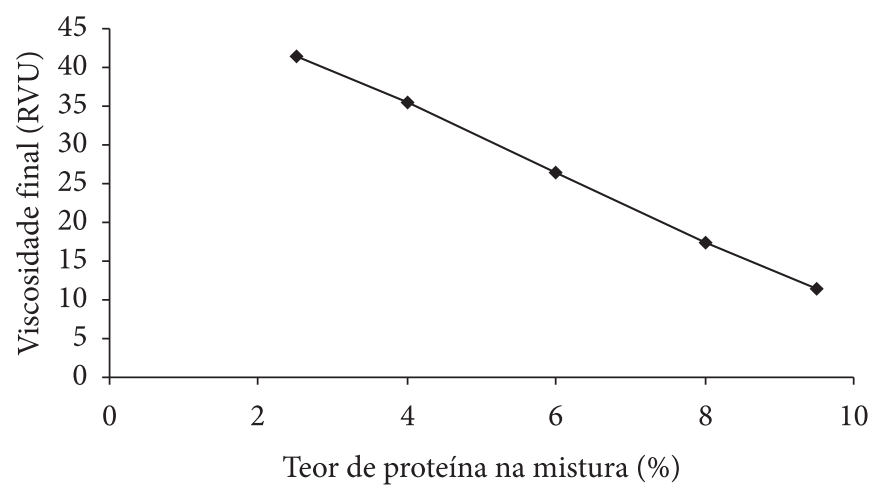

Figura 7. Efeito do teor de proteína sobre a viscosidade final das misturas extrusadas, com umidade de $16 \%$ e temperatura de extrusão de $100{ }^{\circ} \mathrm{C}$.

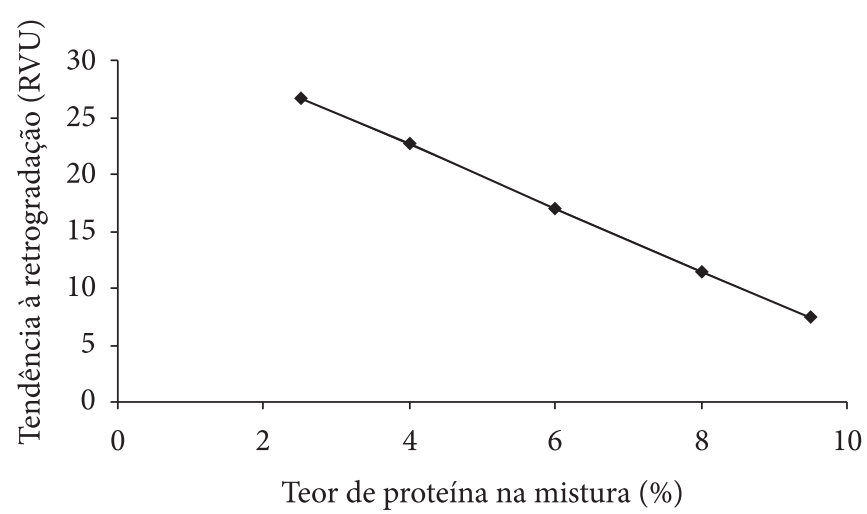

Figura 8. Efeito do teor de proteína sobre a tendência à retrogradação das misturas extrusadas, com umidade de $16 \%$ e temperatura de extrusão de $100^{\circ} \mathrm{C}$. 
também, em aumento da viscosidade a frio. As viscosidades de pico, de manutenção a $95^{\circ} \mathrm{C}$, final a $25^{\circ} \mathrm{C}$ e de quebra, bem como, a retrogradação das farinhas de trigo e soja pré-cozidas, contendo $10 \%$ de soja, aumentaram com o incremento da temperatura, e o nível intermediário de umidade (26\%) resultou em maiores valores.

\section{Conclusões}

Os resultados obtidos mostraram que o teor de proteína nas misturas de farinha de mandioca e caseína foi a variável de maior significância, exercendo efeito sobre todas as propriedades de pasta, seguida pela umidade das misturas que influenciou a viscosidade inicial, o pico de viscosidade e a quebra de viscosidade. A combinação das condições de alta temperatura de extrusão com baixa umidade e teor médio de proteína na mistura de farinha de mandioca e caseína, testadas neste experimento, proporcionam valores intermediários de propriedades de pasta, o que é desejável em produtos instantâneos.

\section{Agradecimentos}

Os autores agradecem à Fundação de Amparo à Pesquisa do Estado de São Paulo o auxílio financeiro concedido.

\section{Referências bibliográficas}

ALVIM, I. D.; SGARBIERI, V. C.; CHANG, Y. K. Desenvolvimento de farinhas mistas extrusadas à base de farinha de milho, derivados de levedura e caseína. Ciência e Tecnologia de Alimentos, v. 22, n. 2, p.170-176, 2002.

ANGELIS, R. C. Valor nutricional das proteínas; métodos de avaliação. Cadernos de Nutrição, v. 10, p. 8-29, 1995.

BORGES, G. G. et al. Viscosidad de pasta, absorcion de água y absorción de grasa de gachas deshidratadas elaboradas con maiz y soya. Alimentaria, v. 35, n. 295, p. 63-66, 1998.

CARVALHO, R. V.; ASCHERI, J. L. R.; CAL-VIDAL, J. Efeito dos parâmetros de extrusão nas propriedades físicas de extrusados (3G) de misturas de farinhas de trigo, arroz e banana. Ciência e Agrotecnologia, v. 26, n. 5, p. 1006-1018, 2002.

CLERICI, M. T. P. S.; EL-DASH, A. A. Características tecnológicas de farinhas de arroz pré-gelatinizadas obtidas por extrusão termoplástica. Ciência e Agrotecnologia, v. 32, n. 5, p. 1543-1550, 2008.

COCHRAN, W. G.; COX, G. M. Experimental designs. United States: Jonh Wiley \& Sons, 1957. p. 396-399.

Companhia Nacional de Abastecimento - CONAB. 2005. Disponível em: www.conab.gov.br. Acesso em: 23 ago. 2006.

DAVIAN, C. et al. Rennet coagulation of skin milk and curd drainage: Effect of $\mathrm{pH}$, casein concentration, ionic strengh and heat tretment. Le Lait, v. 80, n. 4, p. 397-415, 2000.
EL-SAIED, H. M. et al. Gelatinization, pasting characteristics and cooking behavior of Egyptian rice varieties in relation to amylose and proteins content. Starch/Stärke, v. 31, n. 8, p. 270-274, 1979.

FELLOWS, P. Extrusão. In: FELLOWS, P. Tecnologia do Processamento de Alimentos: princípios e prática. Porto Alegre: [s.n.], 2006. cap. 14, p. 305-319.

GAUCHERON, F.; LE GRAËT, Y.; BRIARD, V. Effect of sodium chloride addition on the mineral equilibrium of concentrated and acidified casein micelles. Milchwissenschaft, v. 55, n. 2, p. 82-6, 2000.

GIESE, J. Proteins as ingredients: types, functions, applications. Food Technology, v. 48, n. 10, p. 50-60, 1994.

GUHA, M.; ALI, S. Z.; BHATTACHARYA, S. Effect of barrel temperature and screw speed on rapid viscoanylyzer pasting behavior of rice extruded. International Journal of Food Science and Technology, v. 33, p. 259-266, 1998.

GUTKOSKI, L. C.; EL-DASH, A. A. Effect of extrusion process variables on physical and chemical properties of extruded oat porducts. Plant Foods for Human Nutrition, v. 54, p. 315-325, 1999.

LEMOS, L. B. et al. Características de cozimento e hidratação de grãos de genótipos de feijão comum (Phaseolus vulgaris L.). Alimentação e Nutrição, v. 7, p. 47-57, 1996.

MAIA, L. H. et al. Viscosidade de pasta, absorção de água e índice de solubilidade em água dos mingaus desidratados de arroz e soja. Ciência e Tecnologia de Alimentos, v. 19, n. 3, p. 391-396, 1999.

MENEGASSI, B. et al. Efeito de parâmetros de extrusão na cor e propriedades de pasta da farinha de mandioquinha-salsa (Arracacia xanthorrhiza). Ciência e Agrotecnologia, v. 31, n. 6, p. 1780-1792, 2007.

NEWPORT SCIENTIFIC. Operation manual for series 4: Instrutions Manual. Warriewood, Austrália: [s.n.], 1998. p. 123.

SEBIO, L. Efeito de alguns parâmetros operacionais de extrusão nas propriedades físico-químicas da farinha de inhame (Dioscorea rotundata). 106 f. Dissertação (Mestrado)-Faculdade de Engenharia de Alimentos, Universidade Estadual de Campinas, Campinas, 1996.

SGARBIERI, V. C. Proteínas em alimentos protéicos: propriedades, degradações, modificações. São Paulo: Varela, 1996. 357 p.

SILVEIRA, E. T. F. et al. Farinha composta de resíduo do extrato de soja e de arroz em mistura com trigo para uso em panificação. Boletim do Instituto de Tecnologia de Alimentos, v. 18, n. 4, p. 543-561, 1981.

WANG, S. H. et al. Farinhas de trigo e soja pré-cozidas por extrusão para massas de pizza. Pesquisa Agropecuária Brasileira, v. 40, n. 4, p. 389-395, 2005.

WHALEN, P. J. et al. Measurement of extrusion effects by viscosity profile using rapid viscoanalyser. Cereal Foods World, v. 42, n. 6, p. $469-475,1997$. 